\section{Gender, performance, and self-efficacy in STEM-related careers}

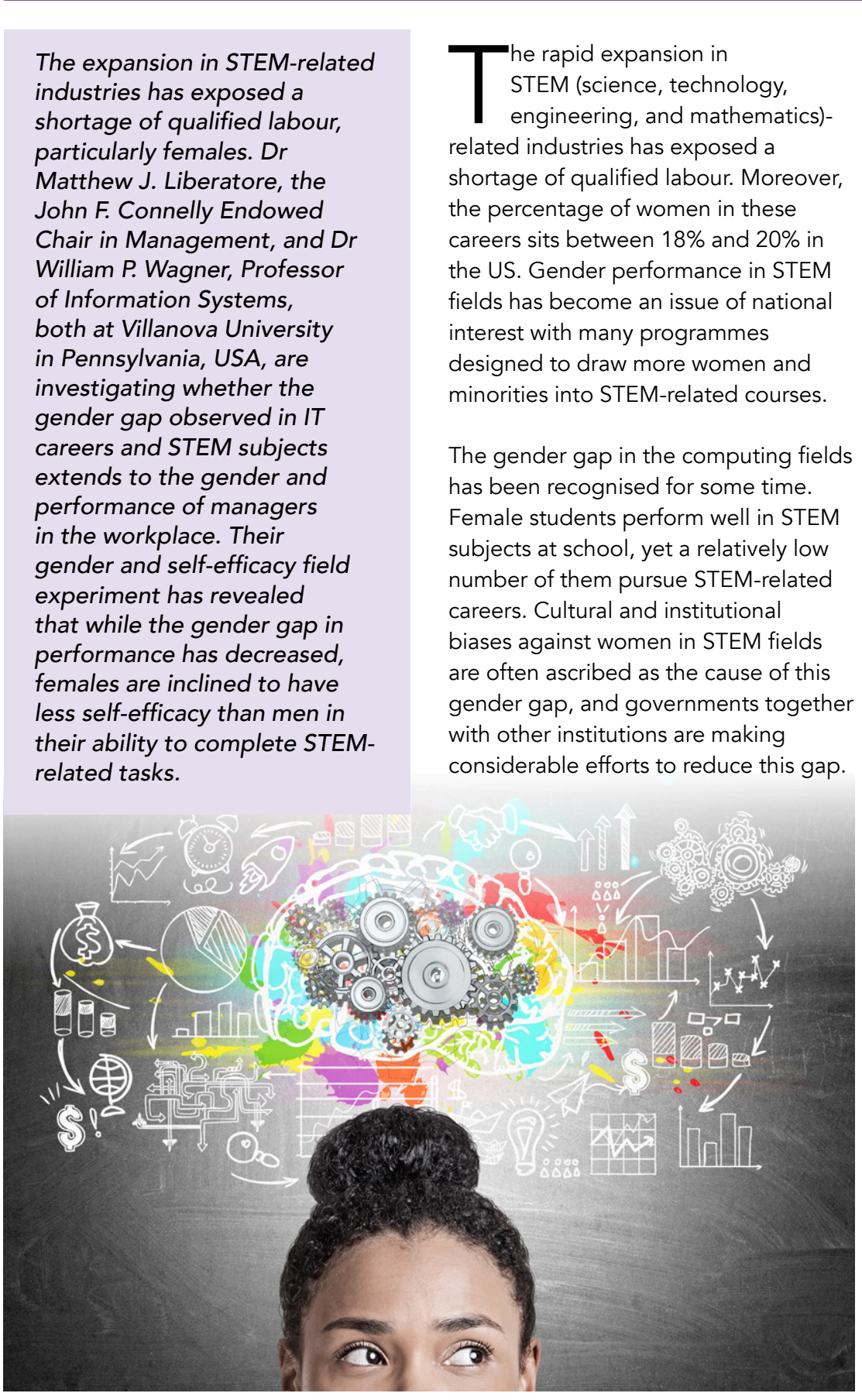

Dr Matthew J. Liberatore, the John F. Connelly Endowed Chair in Management at Villanova University, and Dr Willam P. Wagner, Professor of University, are investigating whether the gender gap in IT careers and school performance in STEM subjects extends to the performance of men and women in the workplace. Furthermore, they are examining whether there are differences in self-efficacy among men and women in the workforce. Their findings have prompted the researchers to recommend a broad agenda of change in order to advance gender equity in STEM fields.

\section{GENDER AND SELF-EFFICACY} Recent gender and performance studies of students in an educational context indicate that, while the gender gap in performance has decreased self-efficacy, in that wo have less to be less confident in their ability to complete STEM-related tasks than men. Self-efficacy is a psychologica construct that refers to an individual's personal belief in their capability to complete a specific task in order to achieve particular attainments. Prof Liberatore and Prof Wagner explain that people generally set their own targets in line with their personal perceptio of their self-efficacy. People make career choices based on self-efficacy
- accordingly, it is one of the main - accordingly, it is one of the main Theory, a career choice model. The Theory, a career choice model. The this model in elucidating why women are inclined to avoin

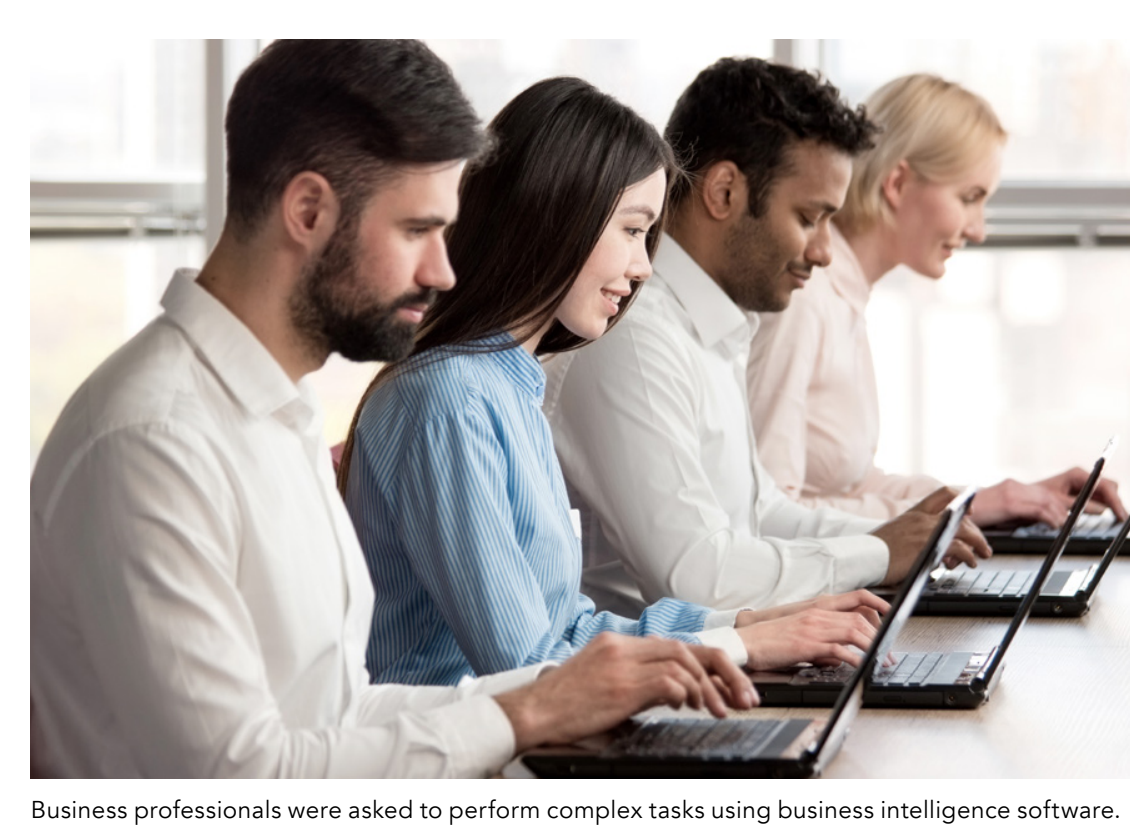

Previous research has shown that - sady experis ant to explore how well and women perceive their self-efficacy field would perform complex tasks with mobile learning technology and using laptops and tablets in different in the mathematics classroom. In both scenarios involving both stationary

Cultural and institutional biases against women in STEM fields are often ascribed as the cause of this gender gap.

cases, women perceived themselves to be considerably less able than the male counterparts.

To date, studies of self-efficacy relating to gender and STEM have in an educationa cortextipants in an educational context. Prof expanding research in this area in their investigation as to whether the selfefficacy gender gap exists in the case of managers in the workforce using business intelligence software. Previous research has led the researchers to assume that there would be gender and performance differences, but whether the females would outperform the

\section{GENDER AND SELF-EFFICACY} FIELD EXPERIMENT

The researchers hypothesised that there would be a gender difference in self-efficacy relating to the participants' performance in tasks using the business and Prof Wagner designed a field and mobile computing environments. whether there were self-efficacy differences between male and female participants and how they judged the performance on the given tasks.

Business professionals from 12 different corporate sites and others taking

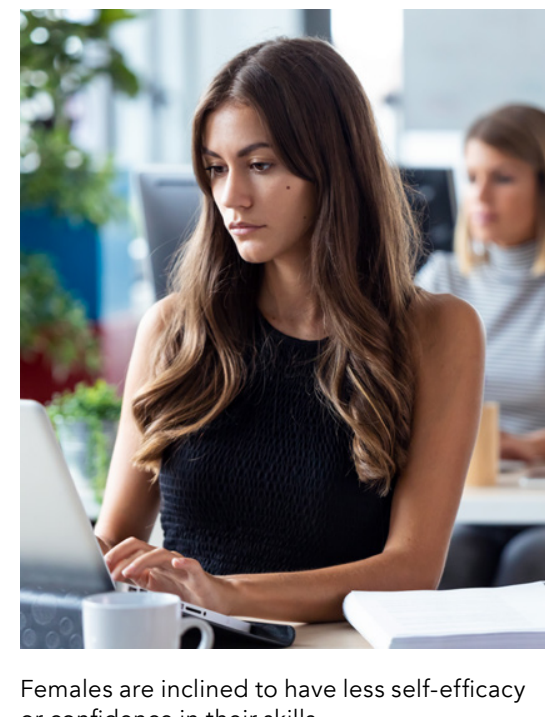
In addition, they would investigate the part-time MBA Programme this study A totst of 239 merited for participated in the study 139 males and 100 females. The male and female subpopulations were similar both in terms of their demographics and their knowledge. There were no statistically significant differences regarding the participants' length of work experience, age, business position and company size. Nor were there disparities in the participants' self-assessed knowledge of tablets and laptops. The male subpopulation had a slightly higher percentage of graduate degrees, but this was outside the range of statistica significance. Given the participants similanty, results from this study provide gronder gender gap continues beyond the people's use of technology.

The subjects were randomly assigned one of three treatments: laptop stationary, where the participant completed the study seated using a laptop; tablet stationary, where the participant completed the study seated using a tablet; and tablet mobile, where the subject was issued with an identica tablet and performed the training seated but completed the subsequen tasks while standing or walking slowly.

Participants were trained in the use of the business intelligence software and given access to a set of sales data. They questions relating to an analysis of the data set These questions were set at three levels of difficulty. The sessions were also captured on video.

ANALYSIS OF THE RESULTS In terms of the levels of difficulty, male participants were significantly more accurate on the tablet seated scenario with the basic questions and the basic questions overall. There were no significant differences, however, in accuracy between genders with the medium and advanced questions, when analysed overall and separately. Crucially, no significant differences were observed between genders in accuracy each of the three computing scenorios each of the three computing scenarios 

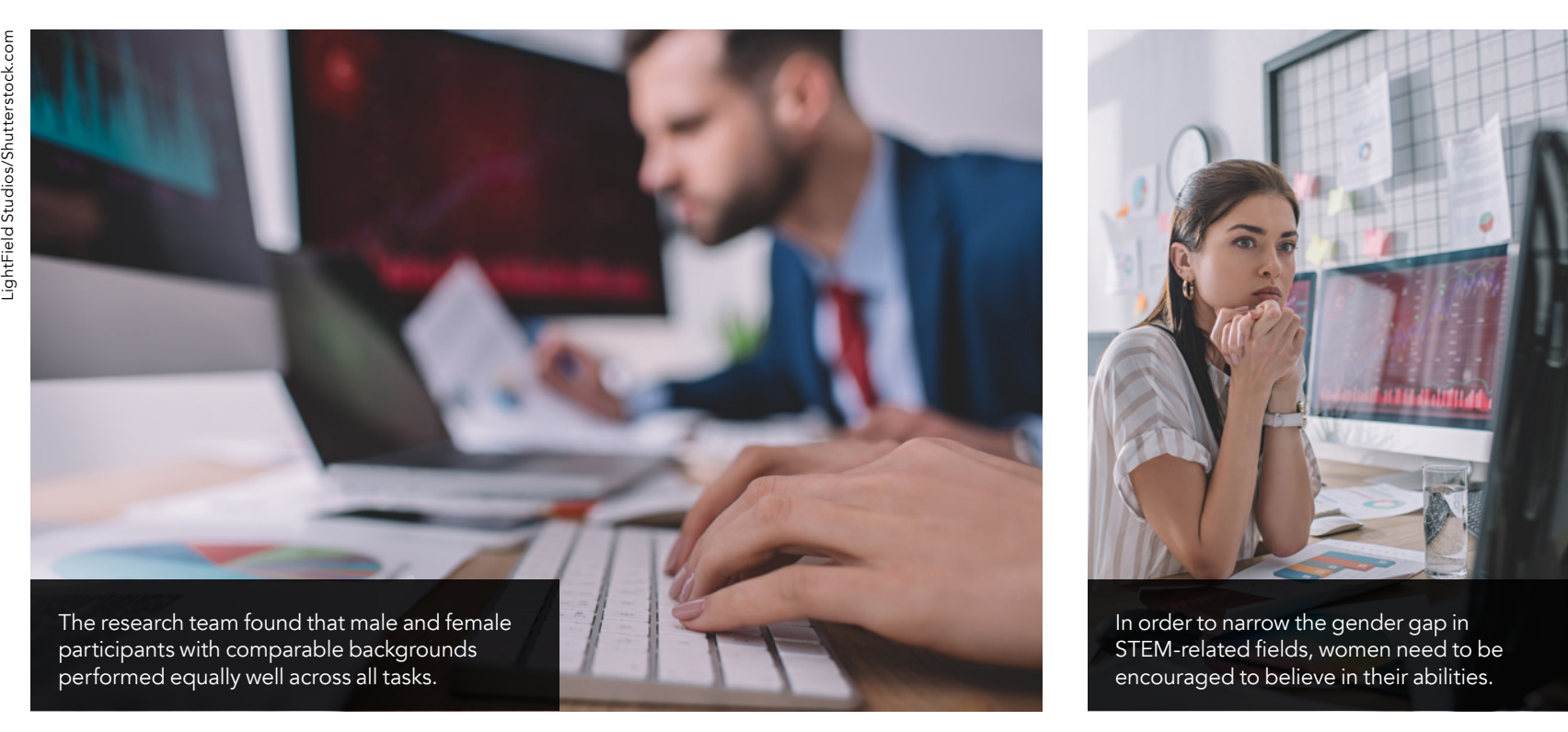

analysed. Moreover, there were no significant differences between genders in the time taken to perform the tasks. were no significant differences there male and female participants with respect to their demographics and backgrounds. Furthermore, male and female participants with comparable experience and backgrounds performed equally well across all of the business intelligence tasks in the field study apart from one exception involving accuracy on the basic questions, as previously mentioned.

These results underpin the researchers' conclusion that the gender gap has substantially narrowed as far
as user performance is concerned. as user performance is concerned. severtheless, the study reveals a and female participants with respect to their self-efficacy in completing the business intelligence tasks. The findings disclose that male participants' confidence in completing all of the tasks was significantly greater than that of the female participants. Interestingly the female subjects' confidence, or selfefficacy, was not linked to their actual performance in the tasks.

BROADER IMPACT

Prof Liberatore and Prof Wagne have observed that the STEM gender gap is not derived from inherent training. The results sies or even training. The results suggest that women believe that they are less
capable of using computers than their

It is only through understanding and minimising this current gap that gender equity can be achieved throughout STEM fields.

male counterparts. Further research are required in order to increase the is required to establish whether this confidence of women in performing results from either cultural or historical computing tasks. It is only through beliefs. Another possible source for understanding and minimising this the gender gap is that traditionally_ current gap that gender equity can be there has been a lack of support from achieved throughout STEM fields. the Information Science academic community for women to achieve Prof Liberatore and Prof Wagner PhDs within this field. In addition, the conclude that "this research validates researchers have noticed that the lack the most recent research indicating a dramatic narrowing in the gender gap academia may be sending a sublininal in overall performance in STEM-related message that it is not an appropriate they advise that additional steps their abilities."

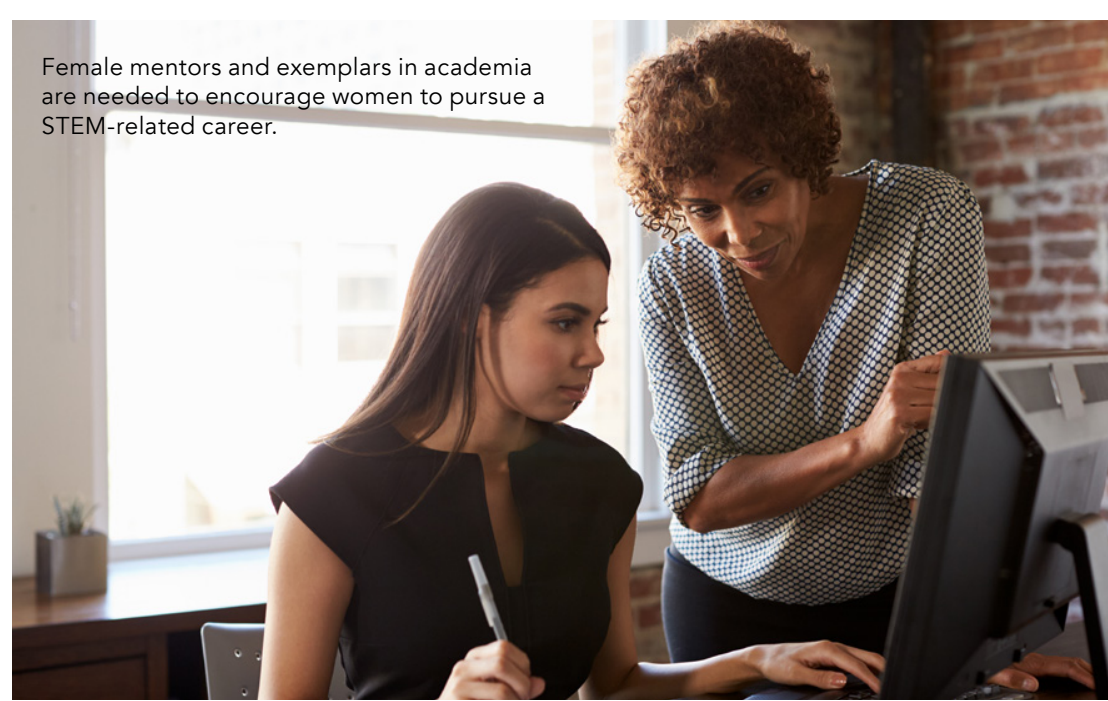

\section{Behind the Research}

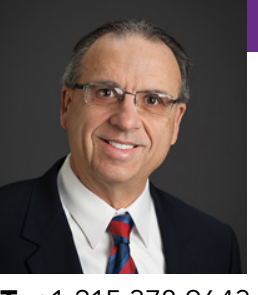

Dr Matthew Liberatore

E: matthew.liberatore@villanova.e

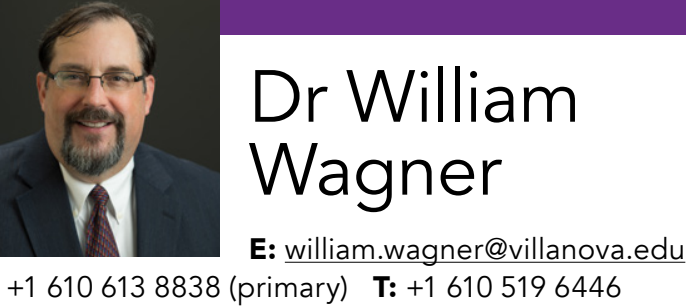

Research Objectives

Prof Liberatore and Prof Wagner investigate whether the gender gap in STEM careers extends to men and women's performance in the workplace.

\section{Detail}

Matthew Liberatore
Villanova School of Business

Villanova University

800 Lancaster Avenue

Villanova, PA 19085

Matthew J. Liberatore is

the John F. Connelly Chair in

Management at Villanova University.
He previously served as Associate
Dean, Management Department
Chair and Director of the Center for
Business Analytics. D Liberatore has
published extensively in supply chain
management, operations research/
analytics, information systems,
project management and healthcare

Dr William P. Wagner has been a Professor of Information Systems at Villanova University since 1991. While at Villanova he has co-authored four books and over 35 journal articles in various IT-related fields. In $2019 \mathrm{~h}$ co-authored the first textbook in the world.

\section{References}

Liberatore, M.J. and Wagner, W.P. (2020). Gender, erformance, and Self-Efficacy: A Quasi-Experimental Field Study. Journal of Computer Information Systems, 8874417.2020 .1717397

\section{『VTVILLANOVA BUSINESS}

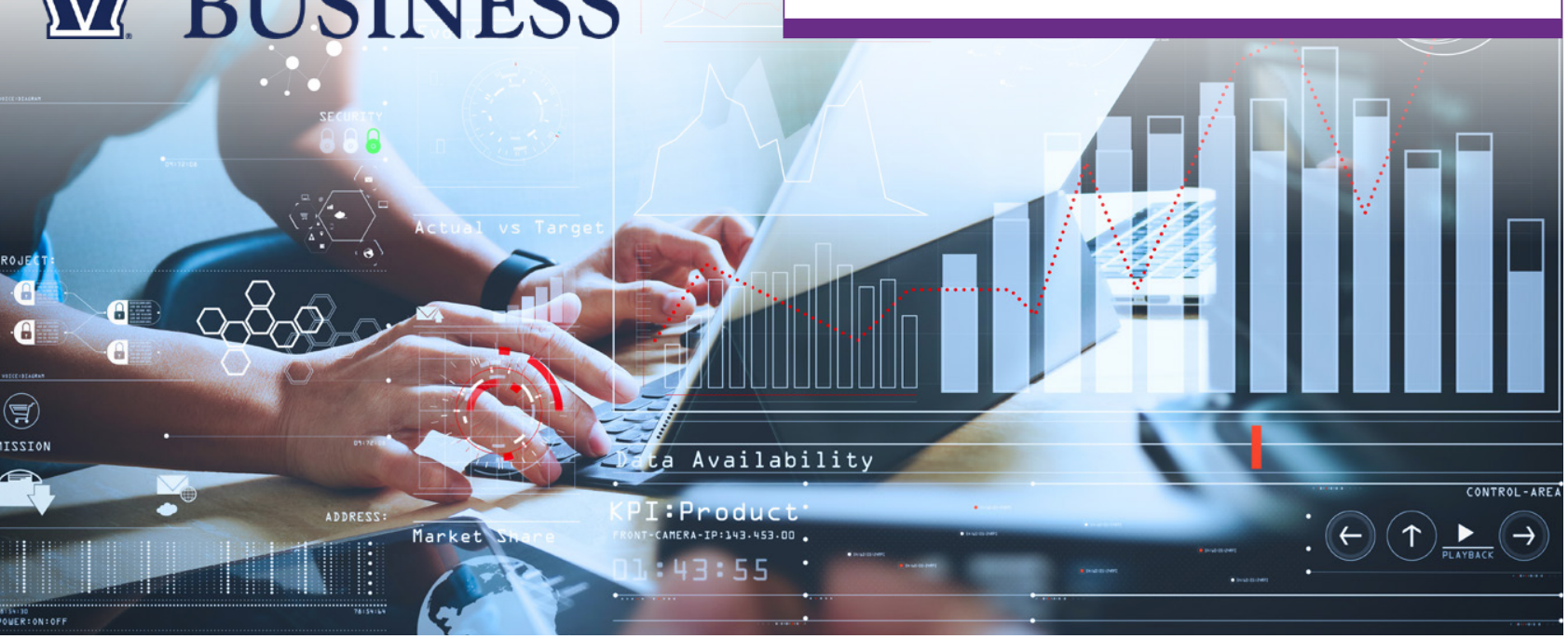

\section{Personal Response}

What would be your advice to educators and employers in order to encourage females to take up

II Both educators and employers should be aware of the special nature of this problem and be prepared to offer practical forms of encouragement such as verbal opertunities for advancement. I

\section{政

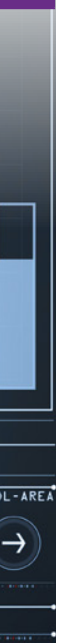

